\title{
Integrative Medicine and the Quest for Humanism in Medicine
}

\author{
Peter Heusser \\ Universität Witten/Herdecke, Germany
}

The recent issues of this journal have repeatedly presented considerations on the use and appropriateness of the term 'integrative medicine' (IM) and its relatives such as 'complementary medicine' (CM), 'complementary and alternative medicine' (CAM), 'integrative and complementary medicine' (CIM). The editorial board has encouraged a broad discussion on the topic; symptomatically, the editors themselves have not yet reached a consistent view on the subject [1]. Internationally, the discussion is not likely to subside in the near future, either. This is not surprising. Even if these terms have first been coined in specific contexts, they have spread globally and are used to designate a large number of quite different non-conventional practices of many cultures and traditions with different forms and degrees of integration into conventional medicine (CON) and health care.

This is not only a disadvantage. Certainly, in the wake of internationalization and globalization of CAM, CAM research and CAM regulation we need clear terms for clear communication. For this reason, the plan to develop a consensus-based terminology to describe CAM interventions within the framework of the EU FP7 project CAMbrella is highly welcome [2]. On the other hand, the complexity and openness of the situation and the struggle to clarify the meanings of these terms sharpen the awareness for what is at stake. This is not so much a semantic issue, but a question as to where the present culture of medicine and healthcare is heading.

To my knowledge, the term 'integrative medicine' was first coined in 1992 by Thilo-Körner [3]. His central tenet was: 'There is no alternative medicine because we do not know of alternative diseases. There is only one medicine, constantly developing and broadening, and the human with its individual disease. Because of the ongoing worldwide discussion about the future development of our medicine I, therefore, suggest the future oriented concept summarized by the term "integrative medicine"" [4]. This was to include the so-called school or scientific medicine, technical medicine, traditional European medicine (Naturheilkunde), homeopathy, spiritual medicine and complementary medicine in the sense of Heisenberg's complementarity - a definition of CM, by the way, which was laid at the basis of this journal in 1994 and is characterized by 'the fact that one and the same phenomenon can sometimes be described by very different, possibly even contradicting images' [4].

It is noteworthy that Thilo-Körner was not a CAM-practitioner, but professor at the Department of Internal Medicine at a university hospital. This may indicate that, within CON itself, the need to extend the conventional scope of health care and to integrate hitherto unconventional elements has been noticed. This is even more true today. For example, the rapidly growing movement of IM in the USA has mainly been created within academic health care centers; dozens of IM centers have been installed at leading university hospitals, and the often cited definition of IM is the one introduced by the Consortium of Academic Health Centers for Integrative Medicine in 2005: 'Integrative medicine is the practice of medicine that reaffirms the importance of the relationship between practitioner and patient, focuses on the whole person, is informed by evidence and makes use of all appropriate therapeutic approaches, health care professionals and disciplines to achieve optimal health and healing' [5]. This definition does not mention CAM at all, although it (can!) implicitly include it; and the self-understanding that goes with it regards IM as the integration of CAM in the paradigmatic and methodological frame of CON. This is sometimes seen as a threat of CAM by CON [6].

However, debates and definitions are in development, and the awareness seems to grow that profound changes are necessary within CON itself in order to meet patients' demands. And it could very well be that CON will not just absorb CAM without changing itself, but also learn something from CAM

\section{KARGER \\ Fax +497614520714 \\ Information@Karger.de}

www.karger.com (c) 2011 S. Karger GmbH, Freiburg

$1661-4119 / 11 / 0184-0172 \$ 38.00 / 0$

Accessible online at:

www.karger.com/fok 
and gradually transform its paradigms and methodological premises in a way that will be mutually integrative. Patients seek CAM not because they do not esteem the undoubtable merits of $\mathrm{CON}$, but apparently because they miss certain aspects in it that they seek in CAM. This includes a more empathetic practitioner-patient relationship, a better consideration of individual needs, more participation in decision making, more possibilities for self-activity such as life-style and nutrition changes, more comprehensive or holistic strategies and a better inclusion of psychosocial and spiritual aspects in health care [7]. Indeed, CAM practitioners have shown to have a more intrinsic motivation and a more holistic philosophy of care than CON practitioners [8]. In 2002, the Swiss Academy for Medical Sciences (SAMW) published the results of a representative survey on the expectations of the Swiss population for the future of medicine and health care [9]. 69\% of the citizens wished more humanism (Menschlichkeit), 58\% more CAM, 27\% more general and family medicine, and only $21 \%$ more high-tech medicine (Spitzenmedizin); in addition, more holism (Ganzheitlichkeit) was one of the mainly desired attributes of future health care.

A prime message of the survey is that the perceived lack of humanistic qualities constitutes a major problem in modern medicine, a fact that has been described repeatedly and is now beginning to be discussed also in medical education: 'Patients are frequently unhappy with medical care because physicians fail to demonstrate humanistic qualities. Immersion in science is a necessary part of medical education but not sufficient. Courses in the history of medicine, the medical narrative in literature, bioethics, medicine and art, and spirituality and medicine will train physicians who will temper technological medicine with a humanistic touch' [10]. For similar reasons 'patient centeredness' has become an important desideratum of good medicine. This necessitates the deliberate cultivation of qualities such as 'compassion, empathy, and responsiveness to the needs, values, and expressed preferences of the individual patient' [11].

However, it will not be sufficient to 'temper technological medicine with a humanistic touch' by adding the history of medicine, humanities, and ethics to the scientific side of the medical curriculum (which by itself would be an enormous, necessary and highly welcome achievement, of course). Science itself will have to immerse more deeply into the central question of any form of humanism: What constitutes a human being? How, for example, can 'holism' be developed, if the whole is held to be nothing but the result of its interacting parts, with no ontological value or causal role by itself? How can the 'psyche' or the 'spirituality' be taken seriously if Du Bois-Reymond's dictum of 1842 still prevails, that 'no other forces are acting in the organism than the plain physico-chemical ones' [12]? How can the human 'individuality' or 'person' become a main focus of patient centeredness, if ontologically the 'individual' or 'personal' is only seen on the physical level of biological markers, genetics, and molecular biology, such as in 'personalized medicine'? What is at stake with IM is not just an integration of CAM into CON, but a deeper and more integrative understanding of the human being. Or, as John Martin put it in 2000: 'Perhaps the great problem of the next 100 years in biology will be to understand what makes the human being a human being' [13]. With its epistemological, conceptual and methodological potential CAM can and certainly has to contribute to the process of gaining this understanding $[14,15]$.

\section{References}

1 Walach H, Brinkhaus B, Heusser P, Michalsen A, Reiter B, Witt C, Lüdtke R: Complementary or integrative - ideas and notions. Forsch Komplementmed 2010;17:215-220.

2 Weidenhammer W, Lewith G, Falkenberg T, Fonnebo V, Johannessen H, Reiter B, Uehleke B, von Ammon K, Baumhöfener F, Brinkhaus B: EU FP7 project 'CAMbrella' to build European research network for complementary and alternative medicine. Forsch Komplementmed 2011;18:69-76.

3 Thilo-Körner DGS: Naturheilkunde in der «Integrativen Medizin» - ihre Chance. Therapeutikon 1992;6:558-559.

4 Thilo-Körner DGS: Naturheilkunde im Rahmen der Integrativen Medizin. Ein zukunftsorientiertes Konzept. Ärztezeitschr Naturheilv 1994;35:613-627.

5 Consortium of Academic Health Centers for Integrative Medicine: Consortium Fact Sheet. www. imconsortium.org/prod/groups/ahc/@pub/@ahc/@ cahcim/documents/content/ahc_content_342554.pdf (accessed July 13, 2011).
6 Walach H: «Integrative Medizin» - die Kolonilisierung des Anderen und die Notwendigkeit des ganz Anderen. Forsch Komplementmed 2010;17:4-6.

7 Bishop FL, Yardley L, Lewith GT: A systematic review of beliefs involved in the use of complementary medicine. J Health Psychol 2007;12:851-867.

8 Marian F, Widmer M, Herren S, Dönges A, Busato A: Physicians' philosophy of care: a comparison of complementary and conventional medicine. Forsch Komplementärmed 2006;13:70-77.

9 Leuenberger P, Longchamp C: Was erwartet die Bevölkerung von der Medizin? Ergebnisse einer Umfrage des GfS-Forschungsinstitutes, Politik und Staat, Bern, im Auftrag der SAMW; in: Stauffacher W, Bircher J (Hrsg): Zukunft der Medizin Schweiz. Basel, Schweizerischer Ärzteverlag 2002, pp 181-235.
10 Halperin EC: Preserving the humanities in medical education. Med Teacher 2010;32:76-79.

11 Institute of Medicine, Committee on Quality of Health Care in America: Crossing the Quality Chasm: A New Health System for the 21st Century. Washington, DC, National Academy Press, 2001.

12 Du Bois-Reymond E: Jugendbriefe von Emil Du Bois-Reymond an Eduard Hallmann. Berlin, Dietrich Reimer, 1918, pp 108.

13 Martin J: The idea is more important than the experiment. Lancet 2000;356:934-937.

14 Heusser P: Anthroposophische Medizin. Beiträge zu einer integrativen medizinischen Anthropologie. Stuttgart, Schattauer, 2011.

15 Kraft K, Stange R: Lehrbuch Naturheilverfahren. Stuttgart, Hippokrates, 2010. 